\title{
Precise Intercomparison of Acids by Differential Potentiometric Titration with Hydrogen Electrodes
}

\author{
Roger G. Bates and Edward Wichers
}

\begin{abstract}
The purity of two preparations of benzoic acid, three of oxalic acid, and three of potassium hydrogen phthalate has been compared by a precise determination of the equivalence of each substance with the same solid reference base, sodium carbonate, the only requirements for which were that its composition be uniform and remain constant throughout the series of measurements. The inflection point in each titration was determined by a differential potentiometric method utilizing two hydrogen electrodes. The procedure, which gives a degree of precision greater than has previously been reported for acidimetric determinations, is described in detail. When about 0.06 equivalent of acid was used in each titration, the reproducibility attainable was better than 0.002 percent. The failure of the inflection point and the equivalence point to coincide exactly has been considered in evaluating the reliability of the procedure.

The purity of one of the samples of benzoic acid, as determined independently from accurate measurements of the freezing point, was 99.997 mole percent. Single crystals of benzoic acid grown from a melt of this material were selected as a reference acid and were regarded to have a purity of 100.000 percent. In terms of this reference, a preparation of potassium hydrogen phthalate consisting of optically perfect crystals was found to have a purity of 100.000 percent. The method is adaptable to a variety of acids and bases and, hence, provides an additional criterion of purity for these substances.
\end{abstract}

\section{Introduction}

In order to increase the accuracy attainable in the titration of acids and bases, it is desirable to have precise methods for evaluating the purity of the several substances that are commonly employed as acidimetric and alkalimetric standards. The composition of such standard substances can often be assessed most conveniently and directly by an acidbase titration, and the internal consistency of a series of acidic or basic standards can only be satisfactorily demonstrated when these procedures are developed to a high degree of precision.

The ordinary simple titration of an acidic substance with a solution of a strong alkali is beset by several well-recognized hazards. Among these are contamination of the solution with atmospheric carbon dioxide; drainage and calibration errors, where volumetric techniques are employed; a change in the titer of a standard solution of alkali; and the disparity between the change point of a chemical indicator and the true equivalence point of the acid-base reaction. Although the accuracy of each titration may, nonetheless, approach 1 part in 10,000, errors are often compounded by the necessity of combining the results of 2 or 3 separate operations to obtain the desired assay value.

The differential electrometric titration developed by MacInnes and Cowperthwaite $[1,2]^{1}$ represents the most significant advance in the technique of acid-base titrations that has been reported up to the present time. In their procedure, an accurately weighed quantity of a solution of sodium hydroxide sufficient to neutralize about 99.7 percent of the acid was allowed to react with the solid sample of the

* Presented before the XVth International Congress of Pure and Applied Chemistry, Lisbon, September 1956.

Italicized figures in brackets indicate the literature references at the end of this paper. acidic substance. The resulting solution was washed into the differential titration vessel and the exact inflection point established by addition of a dilute solution of alkali. The results showed that the method is capable of greater accuracy than is ordinarily attained in acidimetric titrations, even when these are performed with great care.

In the present work, the purity of solid acidic substances has been compared by determining the equivalence of each with a solid reference base, sodium carbonate, the only requirements for which were that its composition be uniform and remain constant throughout the series of measurements. The final adjustment to the inflection point was made, as in the earlier work, by adding a dilute solution of sodium hydroxide. Eight preparations of three acidic substances of unusual analytical interest were selected. These were samples of benzoic acid, oxalic acid, and potassium hydrogen phthalate. The establishment of the inflection point by differential means was studied and certain refinements introduced.

\section{Experimental Procedures}

\subsection{Materiais}

The anhydrous sodium carbonate used in all of the work was a finely granular product, offered by the manufacturer as a "Primary Standard". When the preparations for a series of titrations were being made, an amount of the carbonate sufficient for the series was placed in covered platinum dishes and heated in a muffle furnace at $350^{\circ}$ to $400^{\circ} \mathrm{C}$ for 3 to $4 \mathrm{hr}$, with occasional stirring. It was essential that the carbonate be homogeneous. Hence, before the salt had cooled to room temperature, it was mixed thoroughly by tumbling on glazed paper and was then bottled and stored in a desiccator. 
Two preparations of benzoic acid, three of oxalic acid, and three of potassium hydrogen phthalate were intercompared, these were designated $1 \mathrm{~B}, 2 \mathrm{~B}$, $1 \mathrm{Ox}, 2 \mathrm{Ox}, 3 \mathrm{Ox}, 1 \mathrm{P}, 2 \mathrm{P}$, and $3 \mathrm{P}$. The preparation and purity-evaluation of these substances are described in the following paragraphs.

1 B. Benzoic acid, coarsely granular, from a lot prepared as a reference material for specific-heat calorimetry. The method of purification of this substance, by fractional freezing, and the subsequent treatment to remove water and gases trapped in the crystalline material were the same as those used in preparing the acid for use in thermometric standards issued by the National Bureau of Standards. These procedures are described in two earlier publications $[3,4]$. In fact, the final treatment of the acid and one of the assays for purity were conducted in thermometric cells of the kind described in the second of these publications [4]. The purified acid was transferred from the cells by melting and pouring into platinum dishes, which were stored over phosphorus pentoxide until the acid was frozen, to prevent absorption of moisture by the somewhat hygroscopic liquid acid. The purity of the acid, as estimated from its observed freezing temperature in the thermometric cells, was 99.997 mole percent. The acid was congealed in the platinum dishes and then crushed in an agate mortar and sieved through bronze sieves. The portion used was that passing through a No. 10 sieve (U. S. Standard Sieve Series) and retained on a No. 50 sieve. Benzoic acid in this form is not appreciably hygroscopic in the range of humidities experienced in Washington.

The evaluation of purity referred to above was made by comparing the freezing temperature with that of another lot that had been subjected to more exhaustive purification and whose triple-point temperature was the highest ever observed for benzoic acid at the Bureau. Such a comparison is less sensitive and, in general, less accurate than an evaluation based on observation of the changes of temperature as the substance progressively freezes or melts. Calorimetric observation of the melting curve, that is, measurement of the heat capacity of a substance in the temperature range just below its final melting or initial freezing temperature, is commonly regarded as being the most sensitive and the most reliable means of determining the content of liquid-soluble, solid-insoluble impurities in a substance. This procecure was applied to a portion of the granular product prepared in the manner described. A quantity sufficient to fill a platinum calorimeter vessel [5] was transferred to a glass ampoule, whose neck was sealed to the calorimeter vessel. After evacuation of the assembled apparatus, the benzoic acid was melted and allowed to flow by gravity into the platinum vessel, which was then separated from the glass ampoule by flamesealing.

By the calorimetric procedure, the benzoic acid was found to have a purity of 99.999 mole percent. On the basis of extensive experience with benzoic acid, it is believed that the acid used did not contain impurities of the solid-solution, or mixed-crystal, type in sufficient amount to invalidate the purity estimates of 99.997 and 99.999 mole percent as representing the actual approach to ideal purity that was attained with this substance.

2 B. Benzoic acid, prepared by further purification of the material represented by 1 B. For this preparation the starting material (1 B) was transferred by sublimation to a glass vessel designed for growing single crystals of low-melting substances from their own liquids. ${ }^{2}$ The capacity of this vessel was about $500 \mathrm{ml}$. After the acid was melted, the vessel was slowly lowered, by a clockwork, through a bath composed of two immiscible liquids. The lower layer was maintained at about $100^{\circ} \mathrm{C}$ and the upper layer at $150^{\circ} \mathrm{C}$. There was a sharp discontinuity of temperature at the boundary. As the conical tip of the container passed through this boundary, one, or at most a very few, crystal nuclei were formed, from which growth continued as the vessel was progressively lowered through the temperature boundary. By this procedure, impurities tended to be rejected into the remaining liquid and were thus concentrated in the portion of the sample that was the last to freeze.

In this instance, crystal growth was allowed to proceed at the rate of $0.4 \mathrm{~mm} / \mathrm{hr}$. The total time of freezing was about 3 weeks. When the operation was completed, the vessel was inverted in the bath and heat applied in such a way as to remelt the small portion that was the last to freeze. This liquid was allowed to flow into a bulb in the stem. After the bulb was sealed off, the vessel was restored to its

normal position, the remaining solid was remelted, and the entire operation repeated. The final solid consisted of a large single crystal associated with another portion in which twinning occurred. The vessel was cut open and the single-crystal portion separated from the remainder. The portion of this that was the last to freeze was cut off and the rest transferred to an envelope of platinum foil which was then sealed by gold-soldering so as to exclude further contact with air. The solid acid was crushed to a powder by compressing the foil envelope in a vise.

This preparation of benzoic acid was considered to have ideal purity, subject to the assumption, based on collateral experience, that it did not contain significant impurities present in solid solution. For the purposes of comparison with other acidic substances by titration, it is regarded in this paper as having the exact composition $\mathrm{C}_{6} \mathrm{H}_{5} \mathrm{CO}_{2} \mathrm{H}$.

1 Ox. Anhydrous oxalic acid, finely crystalline, prepared by dehydration of a recrystallized hydrated acid. Dehydration was accomplished by heating at $60^{\circ} \mathrm{C}$ in a vacuum desiccator under a pressure of $1 \mathrm{~mm}$ of mercury. After 7 days, the dehydrated material was ground in a mortar and the powdered acid returned to the desiccator for 7 days at $60^{\circ} \mathrm{C}$. The product was transferred to weighing bottles and weighed in an atmosphere of 15 - to 25 -percent relative humidity. The purpose of this and the other oxalic

\footnotetext{
2 The apparatus and procedure will be described in a forthcoming publication.
} 
acid preparations was to find whether a substance closely approaching the exact composition $\mathrm{H}_{2} \mathrm{C}_{2} \mathrm{O}_{4}$ could be obatined.

$2 \mathbf{O x}$. Anhydrous oxalic acid identical with $1 \mathrm{Ox}$, except that after transfer to weighing bottles, and before weighing, the acid was again placed in a vacuum desiccator at $60^{\circ} \mathrm{C}$ for $18 \mathrm{hr}$. The vacuum was broken with dry air and the bottles capped immediately.

3 Ox. Anhydrous oxalic acid prepared by dehydrating at $60^{\circ} \mathrm{C}$ a product of reagent quality, contained in a flask sealed to a receiving tube, under constant evacuation with a mercury-diffusion pump. After heating at $60^{\circ} \mathrm{C}$ for $28 \mathrm{hr}$, the dehydrated acid was warmed to $100^{\circ} \mathrm{C}$, whereupon it slowly sublimed into the receiving tube during a period of $48 \mathrm{hr}$. After transfer to the weighing bottles, but before the weighings were made, the acid was dried again in vacuum at $60^{\circ} \mathrm{C}$ for $18 \mathrm{hr}$.

1 P. Potassium hydrogen phthalate. The product used was that issued by the National Bureau of Standards as Standard Sample 84d, a standard for acidimetry. This is a granular material containing numerous very small inclusions of the solution from which the substance was crystallized. The water in these inclusions can be removed virtually completely by crushing the crystals to a rather fine powder and drying at about $100^{\circ} \mathrm{C}$. A sufficient amount of the granular standard was crushed and dried in the manner described and stored in a desiccator. This substance is not appreciably hygroscopic in the range of humidities experienced in Washington.

2 P. Potassium hydrogen phthalate. This preparation consisted of portions selected from large single crystals of the substance. These crystals were grown, by the falling-temperature method, in a filtered solution of material identical with $1 \mathrm{P}$. The growing time was about 45 days, and each of the final crystals weighed between 10 and $25 \mathrm{~g}$. The purpose was to eliminate those impurities, including water, that are known or presumed to be present as entrapped mother liquor in the granular material and, by greatly increasing the ratio of volume to surface, to minimize impurities of the type that may be adsorbed on the surface of the granular crystalline product. These are two important sources of impurities in crystalline substances. The recrystallization could not be expected to change materially the content of impurities present in solid solution. From the relatively high purity of the granular material, as determined by the conventional acidimetric assay, this category of possible impurities was thought not to be important.

The large orthorhombic single crystals were not completely free of imperfections. To eliminate impurities that might be associated with these imperfections, the best of the crystals were broken up into flakes about $1.5 \mathrm{~mm}$ thick by systematic cleavages parallel to the [001] faces and the individual pieces painstakingly inspected, selected, and further trimmed, under the microscope, to yield sufficient amounts of small pieces free from discontinuities or inclusions for the intended acidimetric evaluation.

3 P. Potassium hydrogen phthalate. This prep- aration was identical with $2 \mathrm{P}$, except for the further refinement that the trimming of the flakes obtained by cleavage along the [001] faces was accomplished by systematic separation parallel to the weak [100] cleavage plane. The selected small pieces of this preparation, therefore, were bounded entirely by the [001] and [100] cleavage planes and the natural [011] faces. This obviated the ragged surfaces resulting from the unsystematic trimming of the primary cleavage flakes of preparation $2 \mathrm{P}$.

The selected pieces, all of which were inspected with a polarizing microscope at 100 magnifications, were handled exclusively with fire-polished glass implements. To lift and transfer them, gentle suction was applied through a glass tube of small diameter. The inspection and collection of a $10-\mathrm{g}^{\circ}$ sample of this crystalline material required about 2 days.

\subsection{Hydrogen Electrodes}

The bases for the hydrogen electrodes were pieces of platinum foil about $1 \mathrm{~cm}$ square. For titrations of benzoic and oxalic acids, the foils were coated with platinum black by electrolysis for about $1 \frac{1 / 2}{2} \mathrm{~min}$ at a current of $300 \mathrm{ma}$ in a 3 -percent solution of chloroplatinic acid to which lead acetate trihydrate had been added in the amount of $80 \mathrm{mg} / 100 \mathrm{ml}$ of plating solution.

It is well known that the platinum-hydrogen electrode is unstable in solutions of potassium hydrogen phthalate. ${ }^{3}$ Electrodes coated with palladium nevertheless behave well in phthalate solutions [\%]. Hence, the platinum foils were coated with palladium black instead of platinum black for use in solutions of potassium hydrogen phthalate. The plating solution contained about 1 percent of palladium and the same concentration of lead acetate as the platinum solution. The current density and time of plating were the same as for platinizing. $\dot{A}$ piece of palladium strip served as an anode.

The electrodes were freshly prepared for each titration and were stored in distilled water for 1 to 2 hr before use. At the completion of a titration, they were cleaned by dipping in a warm solution composed of 3 parts of concentrated hydrochloric acid, 1 part of concentrated nitric acid, and 4 parts of water. The same portion of this cleaning solution was used repeatedly for stripping platinum and palladium.

The necessity for very pure (oxygen-free) hydrogen was emphasized by MacInnes and Cowperthwaite [1] in their adaptation of the differential method to the use of hydrogen electrodes. The hydrogen used in the present work was passed through a tube of sodalime and through a two-stage purifier consisting of a platinum catalyst at room temperature and a tube containing finely divided copper heated to $500^{\circ} \mathrm{C}$.

\subsection{Method and Apparatus}

The intercomparison consisted essentially in a determination of the weights of each acid stoichiometrically equivalent to a given weight of the refer-

${ }^{3}$ See, for example, references [6] and [7]. 
ence base, sodium carbonate. The purity of the sodium carbonate did not, therefore, influence the result, but it was necessary that the portions of the carbonate used in all the determinations of a given series be identical in composition. Accordingly, all of the portions were transferred, through a powder funnel, into the weighed weighing bottles in as short a time as possible. The transfers, which required only about $30 \mathrm{sec}$ for a series of six, were performed in a dry box at an atmosphere of 15- to 20-percent relative humidity. A glass scoop holding approximately $3 \mathrm{~g}$ of carbonate made this rapid transfer possible.

Potassium hydrogen phthalate and benzoic acid are not appreciably hygroscopic, and the samples of these substances could be adjusted readily to the desired weight, within 1 or $2 \mathrm{mg}$. Anhydrous oxalic acid, however, is converted into the dihydrate if the relative humidity exceeds about 11 percent at $25^{\circ} \mathrm{C}$ $[8]$ and is, accordingly, more hygroscopic than sodium carbonate. For this reason, it was considered desirable to adjust the weight of the carbonate rather than that of the oxalic acid, after an approximate amount had been transferred as described above, to about the quantity required. This final adjustment was made on a balance contained in a dry box. The operation was completed within about 30 min after the bulk of the material was transferred. The weighing bottles were closed when a transfer of carbonate was not actually being made.

The reaction between the acid and the carbonate took place in the flask shown in figure $1(\dot{A})$, provided with a spray trap plugged with platinum gauze. The caps were removed from the weighing bottles containing the samples of carbonate and acid. The larger bottles in which the acid was weighed were lowered into the reaction flask by means of the platinum device shown at B (fig. 1); the smaller carbonate bottles were placed in the flask with a pair of cork-tipped tweezers. The caps were washed with a small quantity of water, the washings being allowed to pass into the flask. Ninety milliliters of water was then added, the spray traps moistened, and the reaction flask stoppered.

In order to effect complete solution of the benzoic acid samples, the reaction flask was placed in a water bath at $70^{\circ}$ after the sodium carbonate was entirely

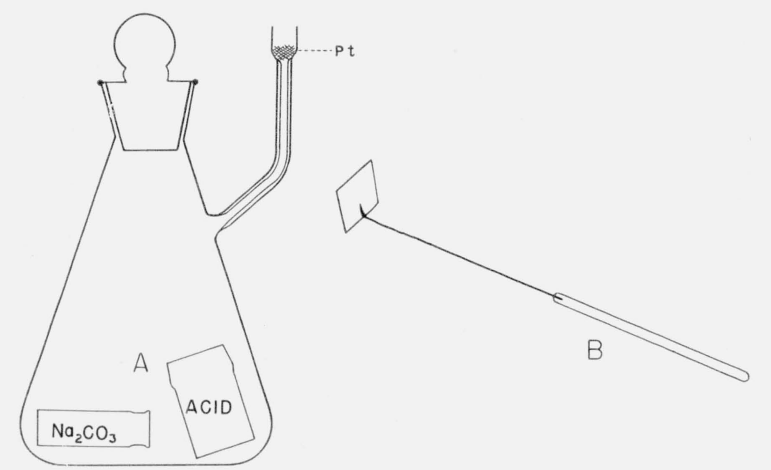

Figure 1. Reaction flask $(A)$ and platinum lowering device $(B)$. dissolved. In the oxalic acid titrations, it was sometimes necessary to warm the flask to dissolve precipitated sodium oxalate. The solution, now containing only a slight excess of the free acid, was rinsed carefully into the cell vessel (A, fig. 2), from which the inner chamber $(\mathrm{g})$ and accessory apparatus had been removed. It was found possible to rinse the reaction flask and the bottles therein thoroughly with about $90 \mathrm{ml}$ of water. The cell was of such size that the total volume of solution could not exceed $225 \mathrm{ml}$ without interfering with the addition of accurately reproducible increments (usually 2 drops) from the tip of the buret.

After the solution had been transferred to the cell, the openings for electrodes, buret, and hydrogen delivery tubes were stoppered. Á tube carrying a sintered-glass thimble at its lower end was inserted in the cell, and a vigorous stream of carbon-dioxidefree hydrogen was passed through the solution for $1 \mathrm{hr}$ to purge it of dissolved carbon dioxide.

A considerable number of preliminary experiments demonstrated that removal of carbon dioxide was incomplete at $p \mathrm{H}$ values exceeding 7 . Accordingly, $p \mathrm{H}$-titration curves in the vicinity of the end point were constructed from measurements with a glass electrode. With the aid of these, an excess of 0.25 percent of oxalic or benzoic acid was found to be sufficient to insure the removal of the carbon dioxide in $1 \mathrm{hr}$, but an excess of 0.7 percent of potassium acid phthalate was required.

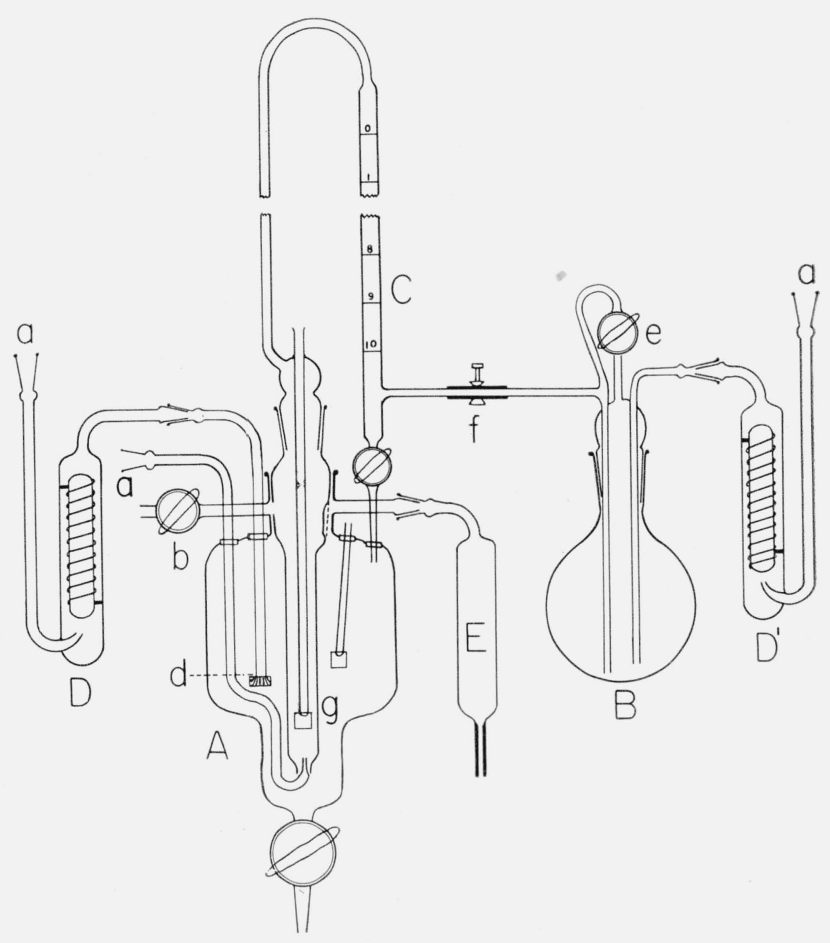

Figure 2. Assembly of apparatus for the differential titration.

A, Titration cell; B, alkali reservoir; C, buret; D, D', hydrogen saturators; E, hydrogen exit chamber; a, hydrogen inlets; b, e, stopcocks; $d$, hydrogen bubbler; $\mathrm{f}$, screw clamp; and $\mathrm{g}$, inner chamber of cell. 
In the intercomparison experiments, the excess of acid was determined by titration with a $0.02-N$ carbonate-free solution of sodium hydroxide, the inflection point being established by the differential method utilizing two hydrogen electrodes. The method derives its precision from the fact that the neutralization takes place to the extent of at least 99.3 percent by reaction of two materials that can be weighed with high accuracy in solid form. A precision of 0.1 percent in the location of the inflection point and in the determination of the excess of acid corresponds to a precision of 0.0007 percent in the equivalence ratio.

\subsection{Determination of the Inflection Point}

After the purging had been completed, the thimble and delivery tubes were rinsed with a small quantity of carbon-dioxide-free water and the apparatus assembled as shown in figure 2. Pure hydrogen was supplied at the three standard-taper joints, a. The jet of gas emerging in fine bubbles from the bubbler, $\mathrm{d}$, of the Branham-Sperling type [9] served both to stir the solution effectively and to furnish the hydrogen electrode in the body of the cell with an adequate supply of gas. In the work of MacInnes and Cowperthwaite [1], a lift pump served the dual function of circulating the solution through the inner chamber $(\mathrm{g})$, whose purpose was to isolate a small portion of solution from the remainder, and of supplying gas to the "retarded" electrode mounted inside this chamber. It was necessary, therefore, to interrupt the flow of gas to the inner electrode when an increment of alkali was added to the bulk of the solution. In the present work, it was believed that somewhat steadier readings were obtained if the flow of hydrogen was maintained. The tube delivering the gas to the inner electrode fitted the aperture at the lower end of the inner chamber rather snugly. The rate of bubbling was reduced during a measurement, and the stability of the potential difference between the electrodes indicated that the two solutions did not mix appreciably.

The $0.02-N$ carbonate-free solution of sodium hydroxide used to titrate the excess acid in the cell was kept in a paraffin-lined flask and was standardized against the Standard Sample of potassium hydrogen phthalate at the beginning and again at the end of each series. In order to remove dissolved oxygen from the alkali, a portion of the alkali solution was placed in flask B, and hydrogen bubbled through it for $1 \mathrm{hr}$ before the buret (C) was filled. The short length of thick-walled rubber tubing at f was impregnated with a paraffin-petrolatum mixture [1]. The saturator, D, prevented deposition of salt by evaporation in the fine passages of the bubbler, $d$, whereas $\mathbf{D}^{\prime}$ guarded the alkali solution in $\mathrm{B}$ from changes of concentration during the purging. Both saturators were filled with distilled water.

Ten to twenty minutes was usually required for the potential difference between the two hydrogen electrodes, as measured by a potentiometer, to drop to 0.1 to $0.2 \mathrm{mv}$. The inner chamber, which had a volume of about $12 \mathrm{ml}$, was occasionally flushed by closing stopcock b. The chamber, E, through which hydrogen escaped from the body of the cell, prevented air from gaining entrance as solution rose again in $\mathrm{g}$. The buret, $\mathrm{C}$, was flushed by the hydrogen escaping from B before it was filled by closing stopcock e. The approximate volume of alkali required to complete the titration was calculated, and $1 \mathrm{ml}$ less than this amount was added after carefully filling the tip of the buret. The chamber, g, was flushed repeatedly until the potential difference was again near zero and the titration continued, with the addition of increments of 2 drops, until the inflection point (as indicated by the peak in the potential difference) had been exceeded by at least $0.5 \mathrm{ml}$. The inner chamber was flushed four times before the addition of each 2-drop increment.

About $3 \mathrm{~g}$ of sodium carbonate was used in most of the determinations reported in this paper, and accordingly the amounts of the acids were approximately as follows: Benzoic acid, $7 \mathrm{~g}$; oxalic acid, $2.8 \mathrm{~g}$; and potassium hydrogen phthalate, $12 \mathrm{~g}$. Somewhat smaller weights of material were used in series II. With these quantities of carbonate and acid, the peak potential differences at the inflection point, resulting from addition of an increment of 2 drops of $0.02-N$ sodium hydroxide, were about 7.5 $\mathrm{mv}$ in the phthalate titrations and 28 to $35 \mathrm{mv}$ in the titrations of the stronger benzoic and oxalic acids. About 18 to $22 \mathrm{ml}$ of the alkali solution was required to titrate the 0.7 percent excess of potassium hydrogen phthalate, whereas 7 to $9 \mathrm{ml}$ was necessary to neutralize the 0.25 percent excess of the other two acids. One milliliter of $0.02-N$ sodium hydroxide is equivalent in neutralizing power to slightly more than $1 \mathrm{mg}$ of sodium carbonate.

In order to locate the inflection point in the titration curve with the greatest possible accuracy, a suitable method of interpolating between successive increments must be sought. For this purpose, either the measured potential difference, $\Delta E$, between the two hydrogen electrodes, or the reciprocal of $\Delta E$, was plotted against some function of the corresponding volume of alkali. The latter was $v_{\mathrm{t}}+v_{\mathrm{i}} / 2$, where $v_{\mathrm{t}}$ is the total volume of alkali used prior to the addition of the increment in question, and $v_{1}$ is the increment volume.

Plots of the potential differences $(\Delta E)$ in the phthalate titrations against this function of the number of milliliters of dilute alkali added were nearly straight lines on either side of the inflection point, as the data for a typical titration (shown at the top of fig. 3) demonstrate. The intersection of these lines was taken to be the true inflection point, and the corresponding quantity of dilute alkali was read from the plot. This method of plotting the data for benzoic and oxalic acids gave curved lines on either side of the inflection point, but the reciprocal plot suggested by Gran [10] gave straight lines, as shown in the bottom half of figure 3 . The volume corresponding to 0.005 percent in the purity of the acid sample is indicated on each of the plots in figure 3 . 

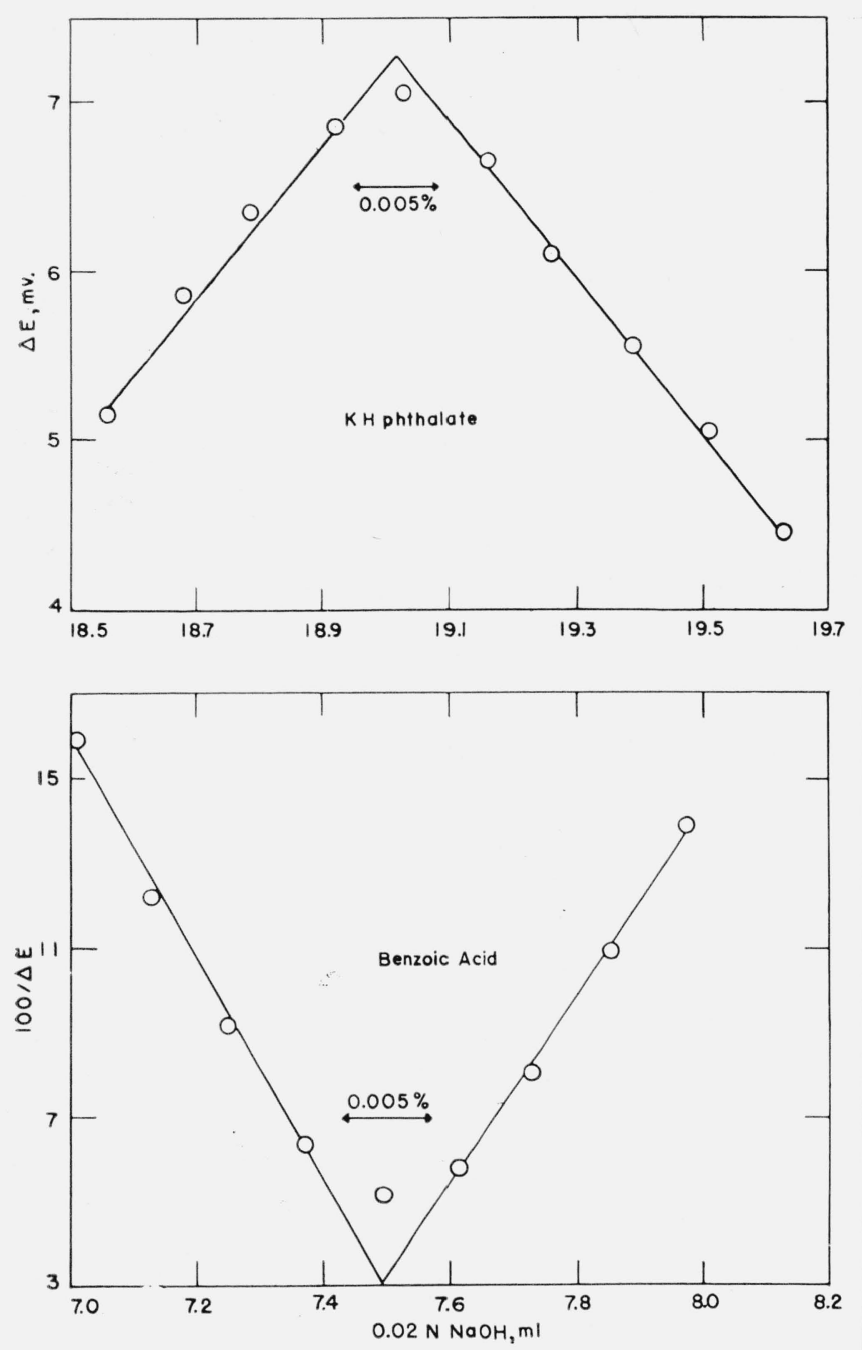

Figure 3. Graphical determination of the inflection point.

\section{Results and Calculations}

\subsection{Design of Experiments}

The determinations were made in four series, designated I, II, III, IV. The first three consisted of six individual titrations, and the fourth consisted of 10. The general pattern used in the first three series was $1-2-3-3-2-1$ and, in the fourth series, 1-2-3$4-5-5-4-3-2-1$, where each number represents 1 of the 8 acid preparations. The repetition of the titrations in reverse order eliminates any linear trend that might cause the result obtained to be influenced by position in the series. The averages are unaffected by a linear drift arising from either known or unknown sources.

\subsection{Weighings}

All of the weighings were made on a semimicrobalance that had a reciprocal sensitivity of 0.007 to $0.008 \mathrm{mg}$ per scale division at a load of 10 to $20 \mathrm{~g}$.
The new set of weights used was calibrated just before the determinations reported here were begun. The corrections to the weights of denominations less than $1 \mathrm{~g}$ were known to $0.001 \mathrm{mg}$. Inasmuch as the rest points were usually reproducible to \pm 1 scale division, or somewhat better than $0.01 \mathrm{mg}$, all weights were recorded to $0.001 \mathrm{mg}$.

The observed weight of each substance was corrected to the vacuum basis. For this purpose, the density of dry air at the temperature and barometric pressure obtaining at the time of the weighing was used. The density of each of the solid materials was determined at $25^{\circ} \mathrm{C}$. A 25-ml volumetric flask served as a pycnometer. The liquids used were benzene (for sodium carbonate, oxalic acid, and potassium hydrogen phthalate) and ligroin (for benzoic acid). The values obtained were 2.42 for the density of sodium carbonate, 1.32 for fused benzoic acid, 1.88 for anhydrous oxalic acid, and 1.62 for potassium hydrogen phthalate.

In view of the drying treatment accorded the oxalic acid preparations $2 \mathrm{Ox}$ and $3 \mathrm{Ox}$, it was necessary to weigh the weighing bottles charged with acid on a different day from that on which the weight of the empty bottles was obtained. The effect of the changed buoyancy of the air was largely nullified by the tare used in all the weighings. The weight of the tare and that of an empty weighing bottle differed in all cases by less than $1.2 \mathrm{~g}$. This difference should cause an error of only 0.0003 percent in the weight of the smallest sample $(2.6 \mathrm{~g})$ of the acid under the conditions of temperature and barometric pressure at the time the two sets of weighings were made.

\subsection{Titration Data}

The results of the 27 determinations are given in tables 1 and 2 . The percentages listed in column 6 of table 2 are based on the arbitrary figure of 100.0000

TABLE 1. Corresponding weights of acids and sodium carbonate

\begin{tabular}{|c|c|c|c|c|}
\hline Acid sample & Series & $\begin{array}{l}\text { Weight of } \\
\text { acid } \\
\text { (vacuum) }\end{array}$ & $\begin{array}{l}\text { Weight of } \\
\mathrm{Na}_{2} \mathrm{CO}_{3} \\
\text { (vacuum) }\end{array}$ & $\frac{\text { Weight of acid }}{\text { Weight of } \mathrm{Na}_{2} \mathrm{CO}_{3}}$ \\
\hline $\begin{array}{l}1 \mathrm{~B} \text { benzoic acid.... } \\
2 \mathrm{~B} \text { benzoic acid.... } \\
1 \text { Ox oxalic acid. } \\
2 \text { Ox oxalic acid } \\
3 \text { Ox oxalic acid } \\
1 \text { P potassium hydro- } \\
\text { gen phthalate } \\
2 \text { P potassium hydro- } \\
\text { gen phthalate } \\
\text { gen potassium hydro- } \\
\text { gen phalate }\end{array}$ & 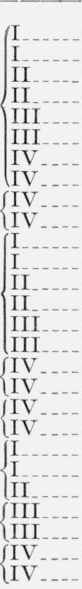 & $\begin{array}{r}g \\
7.147879 \\
7.003172 \\
4.370418 \\
4.567110 \\
6.634762 \\
7.179268 \\
7.286298 \\
6.834195 \\
6.971129 \\
6.448033 \\
2.919566 \\
3.332296 \\
2.530442 \\
2.273362 \\
3.460188 \\
3.303727 \\
3.036824 \\
2.963550 \\
3.173541 \\
2.559824 \\
12.298343 \\
12.246136 \\
7.883861 \\
11.852784 \\
11.177509 \\
11.625558 \\
11.546783\end{array}$ & 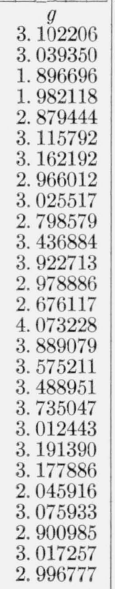 & $\begin{array}{r}2.304128 \\
2.304168 \\
2.304227 \\
2.304156 \\
2.304182 \\
2.304155 \\
2.304192 \\
2.304170 \\
2.304112 \\
2.304038 \\
0.849481 \\
.849488 \\
.849459 \\
.849500 \\
.849495 \\
.849488 \\
.849411 \\
.849410 \\
.849666 \\
.849750 \\
3.853601 \\
3.853548 \\
3.853463 \\
3.853395 \\
3.853005 \\
3.853022 \\
3.853067\end{array}$ \\
\hline
\end{tabular}


TABLe 2. Summary of results

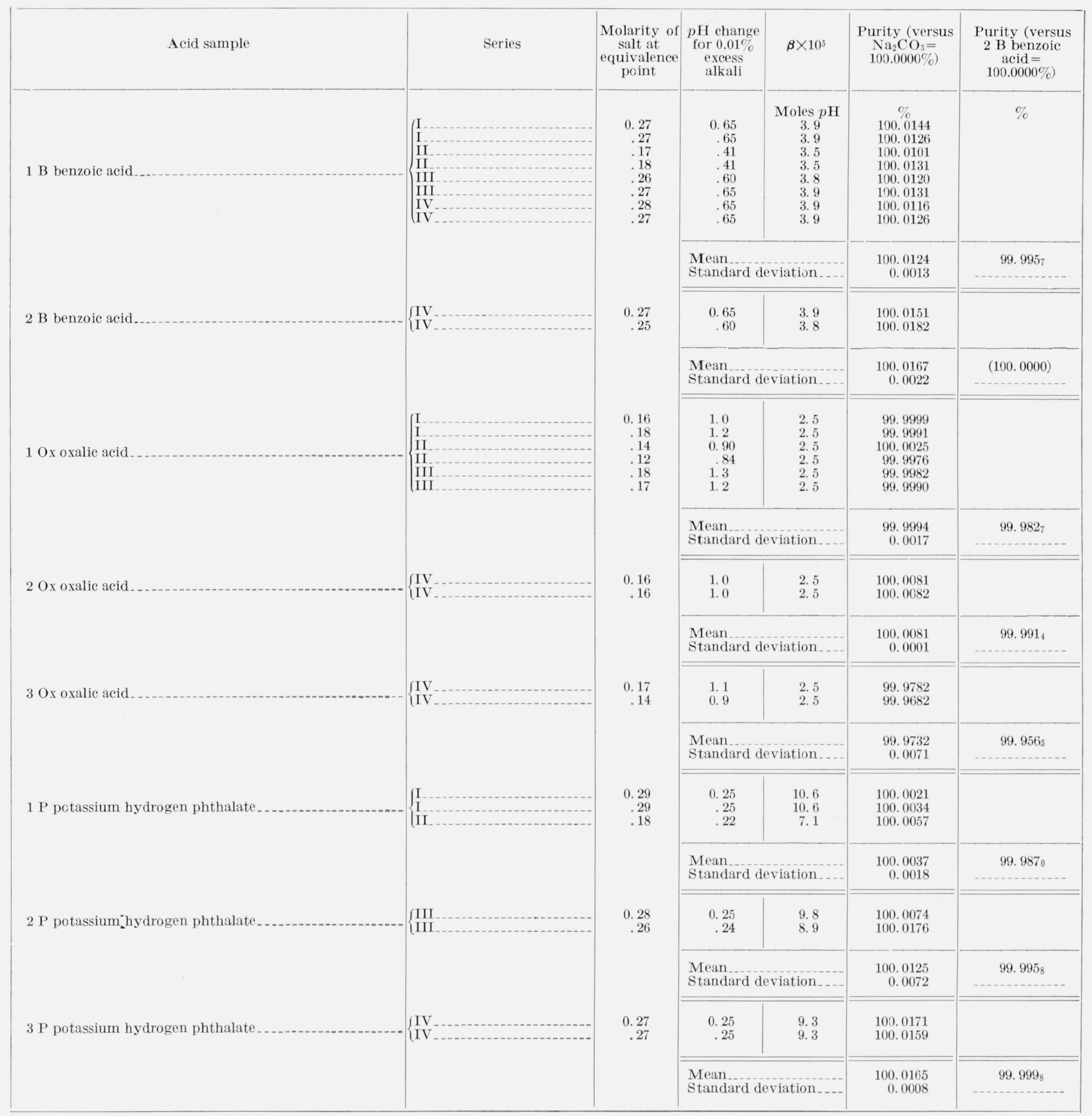

percent for the assay of the sodium carbonate used as a reference base. The mean of all determinations on each acid preparation and the standard deviation of each mean are also found in col: $m n$. The percentages given in column 7 are based on a figure of 100.0000 percent for the purity of the $2 \mathrm{~B}$ benzoic acid, which is believed to be the purest of the eight preparations included in the study. The 1955 atomic weights [11] were used in the computations.

The approximate molarity of salt at the equivalence point is listed in column 3 of table 2 . The $p \mathrm{H}$ change caused by the addition of 0.01 percent of alkali in the immediate vicinity of the inflection point (column 4), and $\beta$, the Van Slyke buffer value [12] near the equivalence point (column 5), indicate the sensitivity of the titrations.

The solubilities of the salts were sufficiently great that large samples of the acids could be conveniently titrated, and the precision of the results was thereby enhanced. It seemed desirable, however, to ascertain whether the results were substantially different when the titrations were performed in a more dilute 
solution. Some titrations of benzoic acid $1 \mathrm{~B}$ and potassium hydrogen phthalate $1 \mathrm{P}$ were accordingly conducted with samples of such size that the concentration of salt at the equivalence point was about $0.05 \mathrm{M}$. The results, expressed in terms of ideal purity for the sodium carbonate, were as follows:

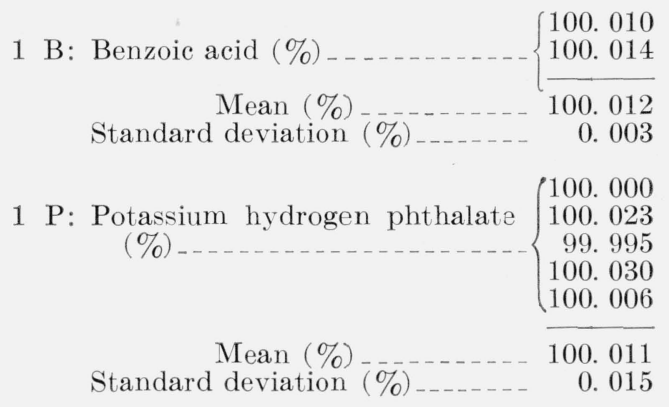

By comparison with column 6 of table 2, it will be seen that the results obtained from the dilute solutions, although of lower precision than those from the more concentrated ones, have the same average value, within the estimated uncertainty of the measurements.

\subsection{Inflection Point Versus Equivalence Point}

It is important to inquire whether the inflection point established electrometrically is indeed the true stoichiometric equivalence point of the neutralization reaction. There are two reasons, one of them experimental and the other theoretical, why this may not be so. The first is the error caused by the isolation of a portion of the solution, not quite brought to the equivalence point, in chamber $g$ when the bulk of the solution is brought to exact equivalence. MacInnes and Dole [13] have shown that this error in volume of reagent cannot exceed $(\mathrm{v} / V) v_{1}$, where $v$ and $V$ are respectively the volumes of the retarded solution and the bulk solution, and $v_{1}$ is the volume of the increment of added alkali solution. In these experiments, $v, V$, and $v_{1}$ were about 12,225 , and $0.12 \mathrm{ml}$, respectively; hence, the error is less than $0.01 \mathrm{ml}$ and alters the final result by considerably less than 0.001 percent.

The other error stems from the well-known fact that as the acids become progressively weaker and hydrolysis of their salts more extensive, the inflection point occurs somewhat before the stoichiometric equivalence point is reached. This matter has been considered in detail by Eastman [14], Roller [15, 16], Kilpi [17], MacInnes [2], and Ricci [18]. These derivations differ somewhat in method and detail, but all lead to substantially the same result.

Roller [15] gives for the difference in $p \mathrm{H}$ at the true equivalence point (ep) and at the inflection point (ip) the expression

$$
(p \mathrm{H})_{\mathrm{ep}}-(p \mathrm{H})_{\mathrm{ip}}=0.65 \sqrt{K_{\mathrm{w}} / c K_{\mathrm{a}}},
$$

where $K_{\mathrm{w}}$ is the ion-product constant for water $\left(K_{\mathrm{w}}=10^{-14}\right.$ at $\left.25^{\circ} \mathrm{C}\right), c$ is the concentration of the salt at the equivalence point, and $K_{\mathrm{a}}$ is the dissociation constant of the weak acid. Equation (1), which applies to the "unsymmetrical" titration of a weak acid with a strong base, indicates that the error is larger the weaker the acid and the smaller the salt concentration at the equivalence point. In the titrations reported here, $c$ varied between 0.12 and $0.29^{6}$ and $K_{\mathrm{a}}$ was in each case greater than $10^{-6}$. Hence, the difference of $p \mathrm{H}$ should be less than 0.001 unit, and the error from this source should be completely negligible.

The comparison of the inflection point with the equivalence point has recently been the subject of a separate experimental study [19]. The course of the titration curve adjacent to, and on both sides of, the inflection point was carefully determined from electrometric titrations in cells with hydrogen and silver-silver-chloride electrodes and without a liquid junction. In every case, the inflection point determined experimentally appeared at a $p \mathrm{H}$ slightly lower than the equivalence point computed from the dissociation constant of the acid and the ion-product constant for water, together with estimated values of the activity coefficients. The differences were, in most instances, somewhat greater than the uncertainties in the calculations and much larger than the estimate afforded by eq (1).

The results pertinent to the titrations reported here are presented in the following summary, where "ip" and "ep" refer to the inflection point and the equivalence point, respectively:

\begin{tabular}{|c|c|c|}
\hline Acid & $\begin{array}{c}\text { Molar concen- } \\
\text { tration of salt } \\
\text { at equivalence } \\
\text { point }\end{array}$ & $(p \mathrm{H})_{\mathrm{ep}}-(p \mathrm{H})_{\mathrm{ip}}$ \\
\hline Benzoic $_{-}$ & $\left\{\begin{array}{l}0.2 \\
.05\end{array}\right.$ & $\begin{array}{r}0.12 \\
.05\end{array}$ \\
\hline Oxalic & $\begin{array}{l}.2 \\
.05\end{array}$ & $\begin{array}{l}.02 \\
.03\end{array}$ \\
\hline Phthalic $--^{-}$ & $\begin{array}{l}2 \\
.05\end{array}$ & $\begin{array}{l}.08 \\
.08\end{array}$ \\
\hline
\end{tabular}

As the concentration of salt at the equivalence point increases, the accuracy with which this point, $(p \mathrm{H})_{\mathrm{ep}}$, can be calculated decreases markedly. Further, for acids as strong as benzoic and oxalic, the inflection point, $(p \mathrm{H})_{\mathrm{ip}}$, is difficult to locate exactly. For these reasons, the tabulated differences must be assigned an uncertainty of at least \pm 0.03 , although there seems to be little doubt that the inflection point precedes the equivalence point by a measurable amount.

The data given in column 4 of table 2 , together with the estimates of the $p \mathrm{H}$ interval between inflection and equivalence points, shed some light on the accuracy with which the purity of two acids can be compared. In this way, it may be judged that the apparent purity versus sodium carbonate as listed in column 6 of table 2 is probably too low by about 0.0025 percent for titrations of benzoic 
acid, by about 0.0003 percent for titrations of oxalic acid, and by about 0.0032 percent for titrations of potassium hydrogen phthalate.

\section{Evaluation of Results}

If the above estimates are valid, the purities relative to preparation $2 \mathrm{~B}$ benzoic acid (table 2 , column 7) should be changed by the following amounts: Oxalic acid, decreased by $0.002_{2}$ percent; potassium hydrogen phthalate, increased by $0.000_{7}$ percent. The corrected figures, relative to $2 \mathrm{~B}$ benzoic acid as ideally pure, become

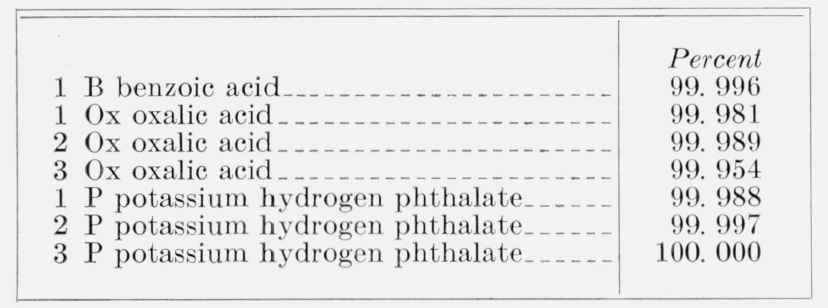

Preparation $3 \mathrm{P}$ potassium hydrogen phthalate appears to be exactly equivalent to benzoic acid $2 \mathrm{~B}$, within the precision of the observations, and therefore may be regarded as having the exact composition $\mathrm{KHC}_{8} \mathrm{H}_{4} \mathrm{O}_{4}$. This equivalence attests the validity of optical perfection in a single crystal as a criterion of the purity of crystalline solids. This criterion is, of course, only applicable when there is assurance of the absence of significant amounts of impurities in solid solution.

Acknowledgements are due the following for services rendered in the highly specialized preparations and for evaluations of purity: To D. Enagonio for the preparation and determination of the purity of benzoic acid $1 \mathrm{~B}$; G. T. Furukawa for the calorimetric purity-evaluation of $1 \mathrm{~B} ; \mathrm{A}$. T. Horton for preparing benzoic acid 2B; W. E. Kuper for growing the single crystals of potassium hydrogen phthalate; C. P. Saylor for the selection of the portions of singlecrystalline phthalate represented by preparations $2 \mathrm{P}$ and $3 \mathrm{P}$; and $\mathrm{W}$. W. Walton for preparing the three lots of anhydrous oxalic acid. The authors are likew ise indebted to N. C. Craig for assistance in preliminary studies and to T. J. Murphy for performing the titrations of dilute phthalate solutions reported in section 3.3 .

\section{References}

[1] D. A. MacInnes and I. A. Cowperthwaite, J. Am. Chem. Soc. 53, 555 (1931).

[2] D. A. MacInnes, The principles of electrochemistry, pp. 306-312 (Reinhold Publishing Corp., New York, N. Y., 1939).

[3] F. W. Schwab and E. Wichers, J. Research NBS 32, 253 (1944) RP1588.

[4] F. W. Schwab and E. Wichers, J. Research NBS 34, 333 (1945) RP1647.

[5] R. B. Scott, C. H. Meyers, R. D. Rands, Jr., F. G. Brickwedde, and N. Bekkedahl, J. Research NBS 35, 39 (1945) RP1661.

[6] C. Z. Draves and H. V. Tartar, J. Am. Chem. Soc. 47, $1226(1925)$

[7] W. J. Hamer and S. F. Acree, J. Research NBS 33, 87 (1944) RP1598.

[8] International critical tables, Vol. VII, p. 245

[9] J. R. Branham and E. O. Sperling, J. Research NBS 22, 701 (1939) RP1214.

[10] G. Gran, Acta Chem. Scand. 4, 559 (1950); Analyst 7\%, 661 (1952).

[11] E. Wichers, J. Am. Chem. Soc. 78, 3235 (1956).

[12] D. D. Van Slyke, J. Biol. Chem. 52, 525 (1922).

[13] D. A. MacInnes and M. Dole, J. Am. Chem. Soc. 51, 1119 (1929).

[14] E. D. Eastman, J. Am. Chem. Soc. 47, 332 (1925); 50, 418 (1928); 56, 2646 (1934).

[15] P. S. Roller, J. Am. Chem. Soc. 50, 1 (1928).

[16] P. S. Roller, J. Am. Chem. Soc. 54, 3485 (1932) ; 57, 98 (1935).

[17] S. Kilpi, Z. physik. Chem. 173, 223, 427, 435 (1935); 175, 239 (1935).

[18] J. E. Ricci, Hydrogen ion concentration, p. 164 (Princeton University Press, Princeton, N. J., 1952).

[19] R. G. Bates and R. G. Canham, unpublished measurements.

Washington, December 3, 1956. 